\title{
Anatomic variant of the inferior lateral cutaneous branch of the radial nerve during the posterior approach to the humerus: a case report
}

\author{
Li Sun ${ }^{1}$, Brian K Park ${ }^{2}$, Salil Gupta ${ }^{3}$, John T Capo ${ }^{3}$, Richard S Yoon ${ }^{2}$ and Frank A Liporace ${ }^{2 *}$
}

\begin{abstract}
latrogenic injury during the posterior approach to the humerus during operative fixation is not an uncommon occurrence. A comprehensive understanding of the normal anatomy and its variants is of paramount importance in order to avoid such injury. Typically, the inferior lateral cutaneous branch of the radial nerve originates towards the distal end of the humerus at the inferior portion of the spiral groove. Here, we report an important variant of this nerve, which originated significantly more proximal than expected, further emphasizing the importance of identification, dissection and protection of the radial nerve and its major branches.
\end{abstract}

Keywords: Anatomic variant, Radial nerve, Lateral cutaneous branch, Humerus fracture

\section{Background}

Understanding normal anatomy and being aware of potential variants is of paramount importance during the operative fixation of fractures. Especially when regarding the radial nerve, injury can occur despite a comprehensive understanding and meticulous dissection [1]. While there have been numerous clinical and cadaveric studies investigating anatomical patterns of the radial nerve, none have described a high-branching variant of the inferior lateral cutaneous nerve [2-9]. Here, we present a case of this anatomic variant we encountered during the posterior approach of humerus during operative fixation.

\section{Case presentation}

Patient is a 27 year-old right hand dominant female who presented initially following an assault where a car door was closed on her right arm. She was evaluated and treated at a local emergency department with a coaptation splint. She had sustained a closed injury and remained neurovascularly intact. Initial management consisted of conversion over to a fracture brace and close follow-up. However, six weeks from injury, the patient endorsed continued pain. Examination revealed tenderness and movement through

\footnotetext{
* Correspondence: liporace33@gmail.com

2Division of Orthopaedic Trauma, Department of Orthopaedic Surgery, NYU Hospital for Joint Diseases, New York, NY, USA

Full list of author information is available at the end of the article
}

the fracture site; radiographs revealed unacceptable angulation and minimal callus formation (Figure 1). With persistent pain, movement through the fracture and minimal healing, the patient was indicated for operative fixation.

The patient was brought to the operating room and placed in the lateral decubitus position. Stress fluoroscopy exhibited gross motion at the fracture site (Figure 2). Via the posterior approach to the humerus, the radial nerve was found approximately two fingerbreadths above the confluence of the triceps lateral head, long head and aponeurosis [8]. Once the main trunk of the radial nerve was found, the surrounding branches were carefully isolated and dissected. The inferior lateral cutaneous branch was found subcutaneously and traced back to its origin (Figure 3). This origin was noted to be a very proximally branching variant of the inferior lateral cutaneous branch, which is typically found at the inferior/distal end of the spiral groove, near the metadiaphyseal junction of the distal third of the humerus [10]. Operative fixation concluded without complication and the wound was closed primarily. The patient healed without complication and at 1-year follow-up was noted to have near full range of motion of the elbow (10-135) and was without complaints (Figure 4A-B).

Iatrogenic nerve injuries are among the devastating complications in the treatment of humerus fractures. Recent studies showed the rate of iatrogenic nerve injury in operatively treated supracondylar humerus fractures 


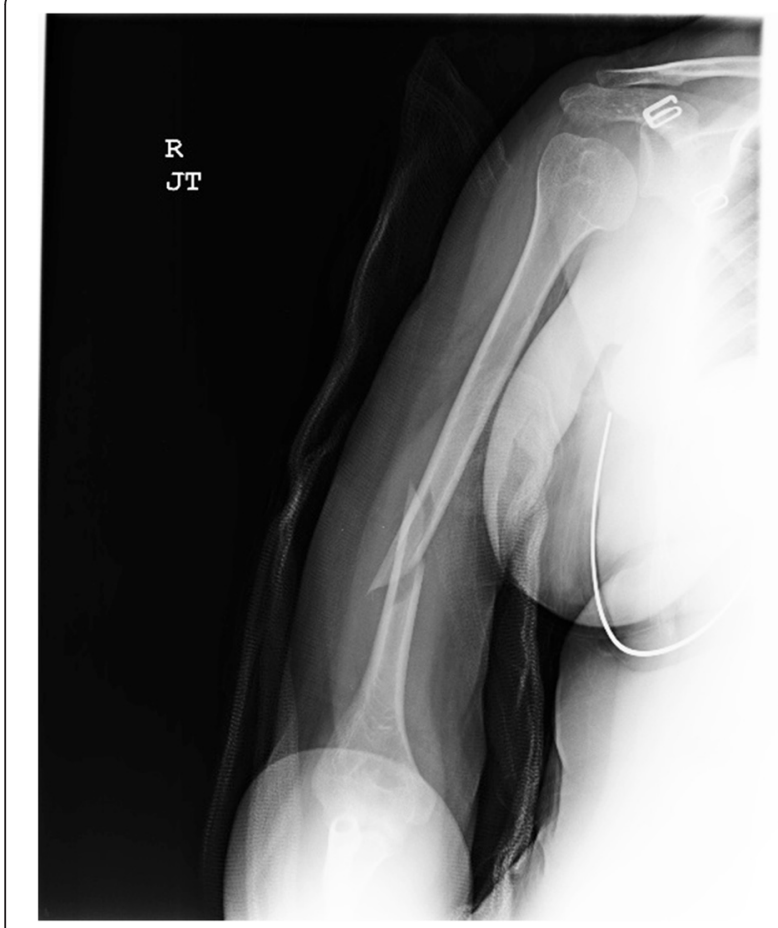

Figure 1 Anteroposterior (AP) view of the humerus at 6 weeks exhibiting malalignment and minimal callus formation.

is $3 \%$ to $4 \%$ [11]. The iatrogenic radial nerve injuries during surgical treatment of humeral shaft fracture could be well over $4 \%$ [1]. With a relatively high rate of potential injury, careful identification and dissection of the nerve and its branches is of paramount importance. Studies of radial nerve with its anatomic location and

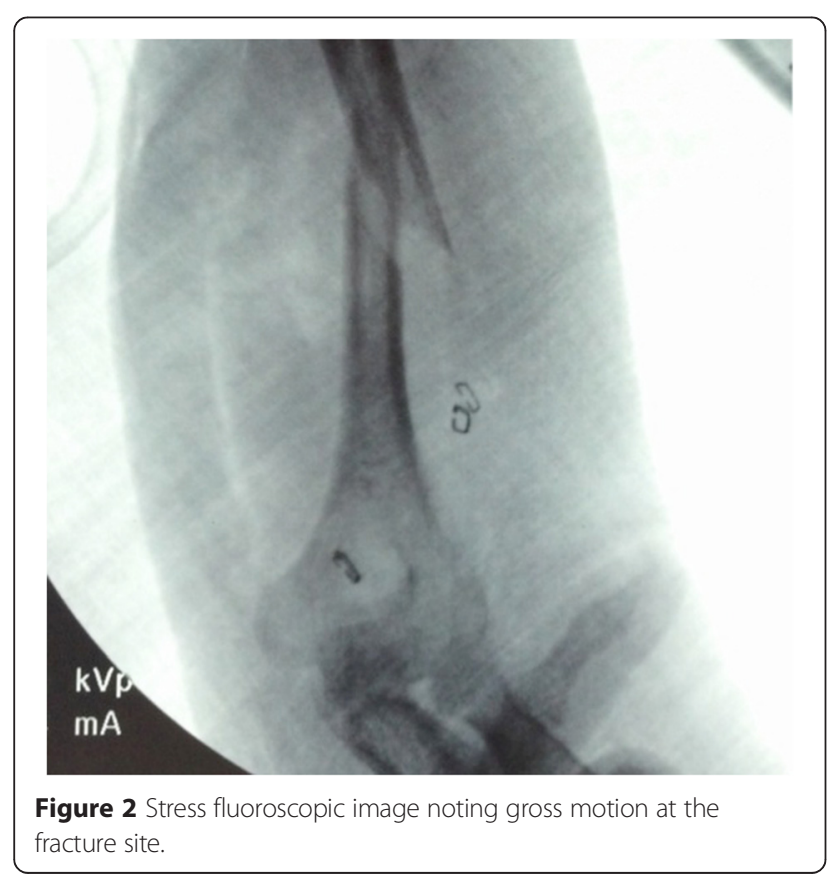

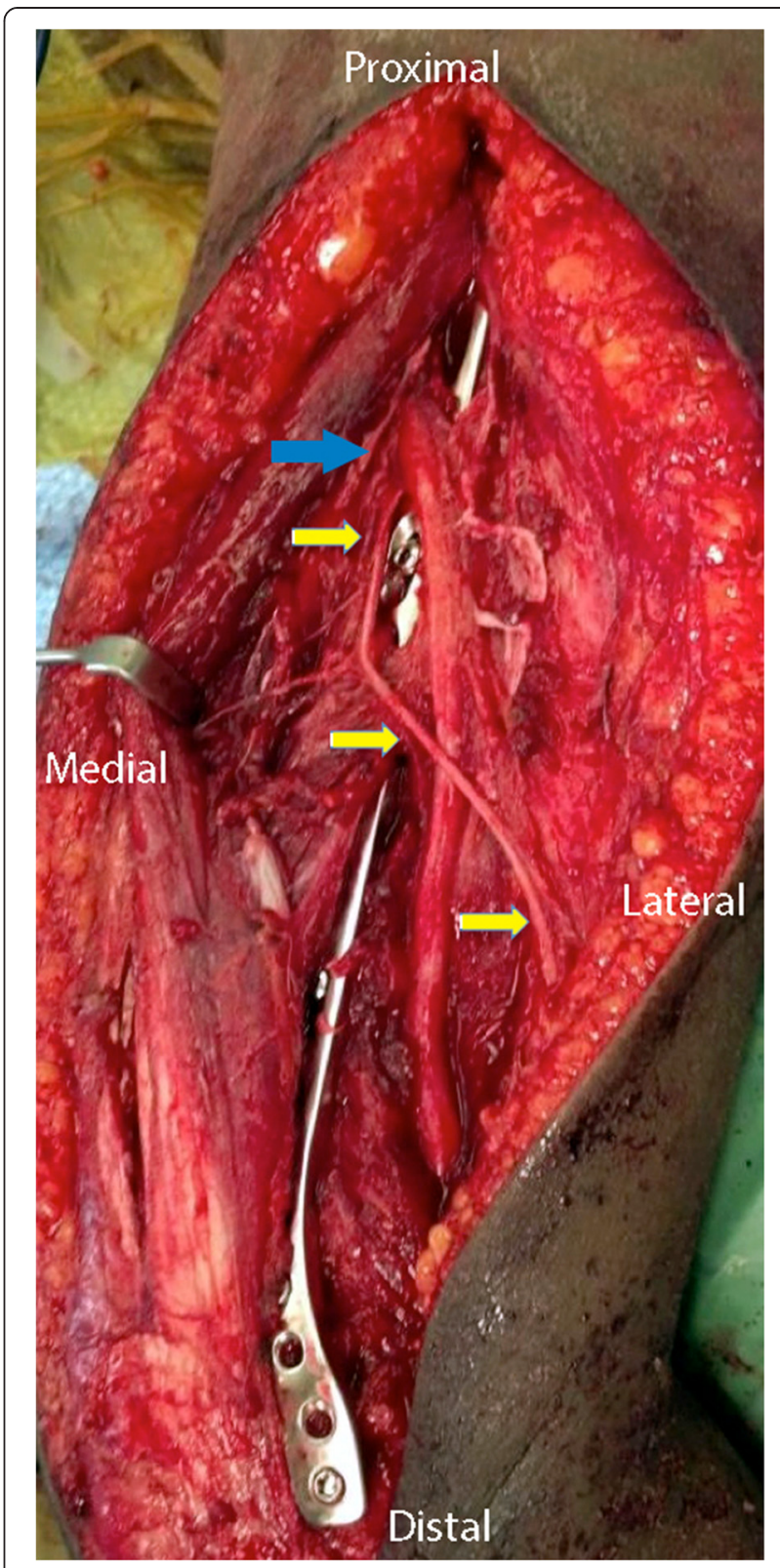

Figure $\mathbf{3}$ Via the posterior approach to the humerus, the inferior lateral cutaneous branch of the radial nerve was traced back to a very high origin (arrows), an anatomical variant from its typical branching location, which would typical be at the inferior/distal end of the spiral groove.

relationship to the surrounding soft tissue and bony structure provide great guidance for the surgical approach in the treatment of humerus fracture. The radial nerve originates from the posterior cord of the brachial plexus passing through the spiral groove on the posterior aspect of the humerus. The radial nerve enters the upper arm through the spiral groove between the lateral head and the medial head of the triceps muscle. Branches in the spiral groove include, posterior cutaneous nerve of the arm, inferior lateral cutaneous nerve of 


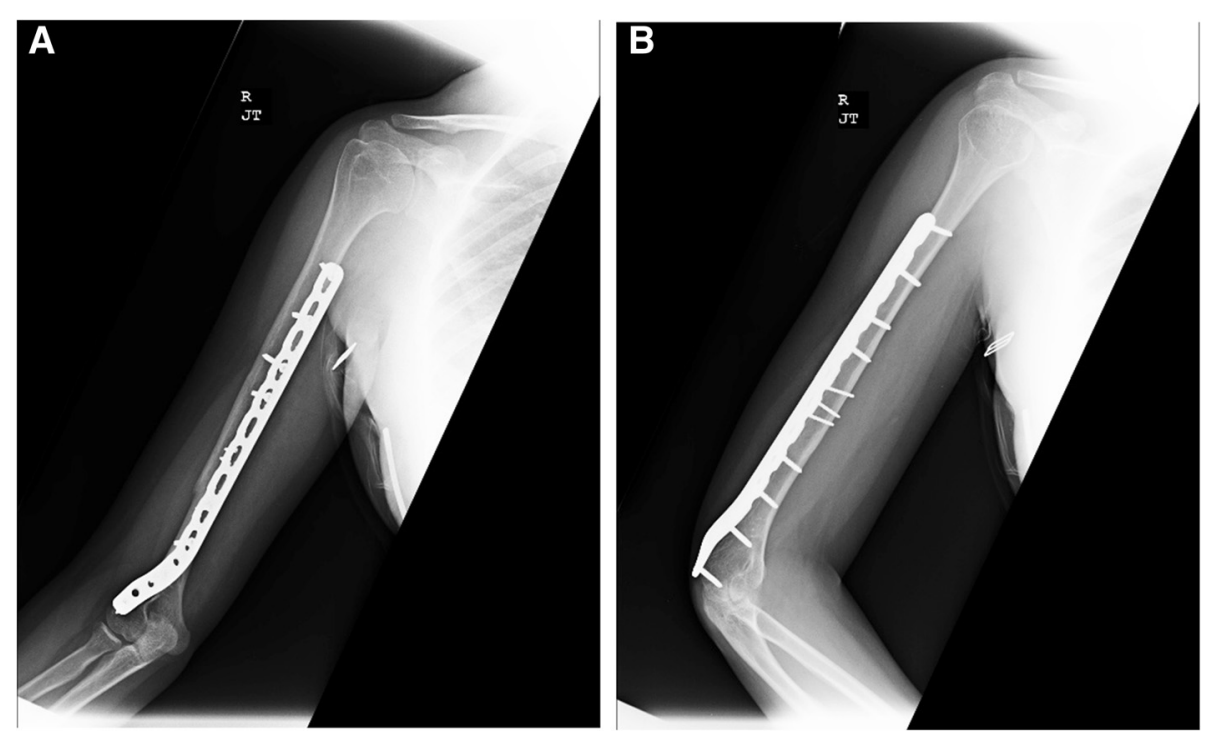

Figure 4 A-B AP and lateral radiographs of the healed right humerus fracture approximately 1 year following operative fixation.

the arm, posterior cutaneous nerve of the forearm, branch to lateral head of triceps, branch to medial head of triceps and anconeus. The 1st branch is the posterior cutaneous nerve of the arm at the groove level. The 2nd branch is the inferior lateral cutaneous nerve of the arm. The inferior lateral cutaneous nerve of the arm arises from the radial nerve at the lower part of the spiral groove, at a mean of $14.2 \mathrm{~cm}$ proximal to the lateral epicondyle [10]. After the radial nerve passes through the spiral groove of the humerus, it then enters the anterior compartment of the arm.

The inferior lateral cutaneous nerve of the arm is the branch of radial nerve that provides sensory and vasomotor innervations to the lower, lateral aspect of the arm. Understanding the variants of sensory nerve not only helps in the identification of radial nerve, but also reduces the chance of iatrogenic injury. In this case, the inferior lateral cutaneous nerve of the arm branched off at the level high above the spiral groove with a long arm branching down laterally into the subcutaneous tissue and skin. Hannouche et al, in a cadaveric study, noted the same takeoff origin of the inferior lateral cutaneous branch in all 18 specimens, which was at the inferior end of the spiral groove [10]. In our case, with such an abnormally proximal branching point of the nerve, this only reemphasizes the importance of careful dissection of the major nerve branches to avoid iatrogenic injury.

\section{Conclusion}

Despite a seemingly reliable anatomic understanding the radial nerve and its branches, we report here an important variant of the inferior lateral cutaneous branch of the radial nerve. Typically, its origin is in the distal third of the humerus at the inferior end of the spiral groove, however, we report an abnormally high branching variant well above even the proximal extent of the spiral groove. We recommend using the confluence of the triceps lateral head, long head and aponeurosis [8] to identify radial nerve then trace proximally towards spiral groove to locate branches of radial nerve, including the possible anatomic variants. Identifying and reporting anatomic variants is essential to reemphasize the importance of dissection and protection of the major branches in order to avoid iatrogenic injury.

\section{Consent}

Informed consent was obtained prior to the completion of this manuscript.

\section{Competing interests}

The authors declare that they have no competing interests.

\section{Authors' contributions}

LS - draft and revisions; BKP - design, draft, revisions; SG - design revisions, final approval; JTC - revisions, final approval; RSY/FAL - conception, design, draft, revisions, final approval. All authors read and approved the final manuscript.

\section{Author details}

'Division of Orthopaedic Trauma, Department of Orthopaedic Surgery, Jersey City Medical Center, Jersey City, NJ, USA. ${ }^{2}$ Division of Orthopaedic Trauma, Department of Orthopaedic Surgery, NYU Hospital for Joint Diseases, New York, NY, USA. ${ }^{3}$ Division of Hand and Upper Extremity Surgery, Department of Orthopaedic Surgery, NYU Hospital for Joint Diseases, 301 E 17th Street, Suite 1402, New York, NY 10003, USA.

Received: 2 February 2015 Accepted: 20 April 2015

Published online: 14 May 2015

\section{References}

1. Wang JP, Shen WJ, Chen WM, Huang CK, Shen YS, Chen TH. latrogenic radial nerve palsy after operative management of humeral shaft fractures. J Trauma. 2009;66(3):800-3 
2. Abrams RA, Ziets RJ, Lieber RL, Botte MJ. Anatomy of the radial nerve motor branches in the forearm. J Hand Surg Am. 1997;22(2):232-7.

3. Carlan D, Pratt J, Patterson JM, Weiland AJ, Boyer MI, Gelberman RH. The radial nerve in the brachium: an anatomic study in human cadavers. J Hand Surg Am. 2007;32(8):1177-82.

4. Cho H, Lee HY, Gil YC, Choi YR, Yang HJ. Topographical anatomy of the radial nerve and its muscular branches related to surface landmarks. Clin Anat. 2012.

5. de Seze MP, Rezzouk J, de Seze M, Uzel M, Lavignolle B, Midy D, et al. Does the motor branch of the long head of the triceps brachii arise from the radial nerve? An anatomic and electromyographic study. Surg Radiol Anat. 2004;26(6):459-61.

6. Defranco MJ, Lawton JN. Radial nerve injuries associated with humeral fractures. J Hand Surg Am. 2006;31(4):655-63.

7. Fleming P, Lenehan B, Sankar R, Folan-Curran J, Curtin W. One-third, twothirds: relationship of the radial nerve to the lateral intermuscular septum in the arm. Clin Anat. 2004;17(1):26-9.

8. Seigerman DA, Choung EW, Yoon RS, Lu M, Frank MA, Gaines LC, et al. Identification of the radial nerve during the posterior approach to the humerus: a cadaveric study. J Orthop Trauma. 2012;26(4):226-8.

9. Uerpairojkit C, Ketwongwiriya S, Leechavengvongs S, Malungpaishrope K, Witoonchart K, Mekrungcharas N, et al. Surgical anatomy of the radial nerve branches to triceps muscle. Clin Anat. 2013;26(3):386-91.

10. Hannouche D, Ballis R, Raould A, Nizard RS, Masquelet AC. A lateral approach to the distal humerus following identification of the cutaneous branches of the radial nerve. J Bone Joint Surg Br. 2009;91(4):552-6.

11. Joiner ER, Skaggs DL, Arkader A, Andras LM, Lightdale-Miric NR, Pace JL, et al. latrogenic nerve injuries in the treatment of supracondylar humerus fractures: are we really just missing nerve injuries on preoperative examination? J Pediatr Orthop. 2014;34(4):388-92.

\section{Submit your next manuscript to BioMed Central and take full advantage of:}

- Convenient online submission

- Thorough peer review

- No space constraints or color figure charges

- Immediate publication on acceptance

- Inclusion in PubMed, CAS, Scopus and Google Scholar

- Research which is freely available for redistribution 